\title{
A Systematic Review of the Efficacy and Safety of Didroxyprogesterone Combined with Progesterone in the Treatment of Luteal Insufficiency-Induced Abortion
}

\begin{abstract}
Yanjing Yang1*, Hongli Zhu ${ }^{2}$
${ }^{1}$ Shaanxi University of traditional Chinese medicine, Xianyang 712046, Shaanxi Province, China

${ }^{2}$ Affiliated Hospital of Shaanxi University of traditional Chinese medicine, Xianyang 712046, Shaanxi Province, China

*Corresponding author: Yanjing Yang, 1157598640@qq.com

Abstract: Objective: To systematically evaluate the efficacy and safety of didroxyprogesterone combined with progesterone in the treatment of luteal insufficiency abortion. Methods: We searched CNKI database, VIP database, Wanfang database, PubMed database, EMBASE database and Cochrane library database for literatures on the treatment of luteal insufficiencyinduced abortion with didroxyprogesterone and progesterone. Meta-analysis was performed using Revman 5.3 software after literature extraction and further quality evaluation. Results: Ten randomized controlled trial-related articles that describe studies on a total of 1145 patients, 570 in the combination group and 575 in the control group, were included. The results of meta-analysis showed that combination therapy could improve the effective rate of fetal protection $(\mathrm{OR}=0.14,95 \% \mathrm{CI}[0.07$, 0.27], $\mathrm{P}<0.00001)$. The safety of the combination group was significantly higher than that of the control group (OR $=3.09$, 95\% CI [1.13,8.48], P=0.03). Conclusion: To sum up, compared with the control group, the combination of progesterone and progesterone is more effective and safer in the treatment of luteal insufficiency abortion. However, the sample size of the data is relatively small and the quality of the literature is low. This conclusion still needs to be further verified in high-quality randomized controlled trials that involve large samples.
\end{abstract}

Keywords: Luteal insufficiency-induced abortion; Didroxyprogesterone; Progesterone; Meta-analysis

Publication date: July 2021; Online publication: July 30, 2021

\section{Introduction}

Threatened abortion is a common complication of early pregnancy, which is mainly related to the lack of luteal function in pregnant women. Luteal insufficiency-induced abortion is the main cause of early abortion due to the decrease of luteal endocrine function in pregnant women, which significantly reduces the secretion of progesterone in the blood, and cannot maintain normal function, leading to menstrual disorders and endometrial differentiation disorders ${ }^{[1]}$. Progesterone functions to maintain reproductive function. Once the progesterone level of pregnant women is below $25 \mathrm{ng} / \mathrm{mL}$, timely intervention is needed, so the main clinical treatment is to supplement progesterone ${ }^{[1]}$, which is commonly used for vaginal bleeding and abdominal pain ${ }^{[2]}$. In the clinical treatment, fetal protection is the main measure for the treatment of threatened abortion ${ }^{[3]}$. The commonly used drugs are didroxyprogesterone and progesterone in different dosage forms. Dydrogesterone is a kind of natural progesterone, which causes less adverse reactions and can inhibit endometrial hyperplasia, protect and repair endometrium, and improve uterine receptivity. Progesterone can inhibit uterine excitability, and reduce embryo rejection through maternal 
immune regulation. The combined use of the two drugs can effectively improve the efficiency of fetal care, ensure high level of safety, and significantly reduce the adverse reactions of patients, and its curative effect is significant. Therefore, through meta-analysis, this paper systematically evaluates the efficacy and safety of didroxyprogesterone combined with progesterone in the treatment of threatened abortion due to luteal insufficiency, so as to provide basis for clinical decision-making.

\section{Data and methods}

\subsection{Inclusion criteria}

(i) Study type: Randomized controlled trial of clinical design

(ii) Research subjects: Women that meet the diagnostic criteria of luteal insufficiency threatened abortion in Obstetrics and Gynecology department ${ }^{[4]}$

(iii)Interventions: The combined group was given progesterone, and the control group was given placebo

(iv)Outcome measures: The efficiency and safety of fetal protection

\subsection{Exclusion criteria}

(i) Non-randomized controlled study, conference literature, animal experiments, etc.

(ii) Individuals with other diseases and those who take drugs that may affect the statistical results of the research subjects

(iii)Subjects who do not meet the inclusion criteria

(iv)Lack of original data, etc.

\subsection{Search strategy}

CNKI, VIP, Wanfang, PubMed, EMBASE and the Cochrane library were searched by computer. The last search time was September 2020. The keywords are: luteal insufficiency; luteal insufficiency abortion; luteal insufficiency abortion; didroxyprogesterone; progesterone; progesterone; randomized controlled trial.

\subsection{Literature screening and data extraction}

Literature retrieved from each database was imported into Noteexpress software, and excel table was established for data extraction and collation. The extracted contents include: (i) basic information; (ii) intervention measures, such as sample size of combination group and control group, dosage, frequency and course of treatment of didroxyprogesterone and progesterone; (iii) outcome indicators; (iv) key elements of bias risk assessment.

\subsection{Methodological quality}

The methodological quality was evaluated using the Cochrane scale.

\subsection{Statistical analysis}

Revman 5.3 software was used for statistical analysis. Odds ratio (OR) was used for binary variables, and mean deviation (SMD) was used for continuous variables, with $95 \%$ confidence interval (CI). In this metaanalysis, Chi-squared test and $\mathrm{I} 2$ test were used for heterogeneity analysis. If $\mathrm{P} \geq 0.1$ and $\mathrm{I} 2<50 \%$, the heterogeneity was small, and fixed effect model was used for analysis. On the contrary, random effect model was used for analysis.

\section{Results}

\subsection{Literature search results}

According to the principle of Picos, 588 articles (196 from CNKI, 312 from Wanfang, 42 from VIP, none 
from PubMed, none from EMBASE, 38 from Cochrane Library) were screened. After reading the full text, 10 articles that describe studies involving a total of 1145 patients, including 570 in the combination group and 575 in the control group, were included.

\subsection{Basic characteristics and quality evaluation results}

The basic characteristics and quality evaluation results of the included articles are shown in Table $\mathbf{1}$ and Figure 1.

Table 1. Basic characteristics and quality evaluation results

\begin{tabular}{|c|c|c|c|c|c|c|c|c|c|c|c|}
\hline \multirow[t]{2}{*}{ Name } & \multirow[t]{2}{*}{ Year } & \multicolumn{2}{|c|}{ Sample size } & \multicolumn{2}{|l|}{ Age } & \multicolumn{2}{|c|}{ Gestational veeks } & \multicolumn{2}{|l|}{ Intervening measure } & \multirow{2}{*}{$\begin{array}{l}\text { Course of } \\
\text { Treatment } \\
\text { (d) }\end{array}$} & \multirow{2}{*}{$\begin{array}{l}\begin{array}{l}\text { Outcome } \\
\text { indexes }\end{array} \\
\end{array}$} \\
\hline & & $T$ & $\mathrm{c}$ & $T$ & C & $T$ & $\mathrm{C}$ & $T$ & C & & \\
\hline $\begin{array}{l}\text { Ouyang } \\
\mathrm{P} \text { [11] }\end{array}$ & 2020 & 33 & 33 & $29.6 \pm 0.5$ & $28.6 \pm 0.5$ & $\begin{array}{l}8.6 \pm \\
0.4\end{array}$ & $9.6 \pm 0.4$ & $\begin{array}{l}\text { Control group + oral } \\
\text { progesterone } 200 \sim \\
300 \mathrm{mg} / \mathrm{d} \text {, once or } \\
\text { twice, dose } \leq 200 \\
\mathrm{mg} / \text { time }\end{array}$ & $\begin{array}{l}\text { Initial oral dose of } \\
\text { dydrogesterone of } 40 \\
\mathrm{mg} \text {, followed by } 10 \mathrm{mg} \\
\text { every } 8 \text { hours }\end{array}$ & \begin{tabular}{|l|} 
Transferenc \\
e cure
\end{tabular} & $1,2,3,4,6$ \\
\hline Zhu H [5] & 2020 & 52 & 52 & $28 \pm 3$ & $7.8 \pm 0.8$ & $28 \pm 4$ & $7.9 \pm 0.9$ & $\begin{array}{l}\text { Control group + oral } \\
\text { dydrogesterone, initial } \\
\text { dose } 40 \mathrm{mg} \text {, then take } \\
10 \mathrm{mg} \text { every } 8 \text { hours }\end{array}$ & \begin{tabular}{|l} 
Intramuscular \\
injection of \\
progesterone, 20 \\
$\mathrm{mg} /$ time, 1 time/d
\end{tabular} & \begin{tabular}{|l|} 
Transferenc \\
e cure
\end{tabular} & $1,2,3,4,6$ \\
\hline$X \cup Q[8]$ & 2019 & 40 & 40 & $30.3 \pm 2.5$ & $30.2 \pm 2.6$ & $\begin{array}{l}9.1 \pm \\
0.4\end{array}$ & $9.2 \pm 0.5$ & \begin{tabular}{|l|} 
Control group + oral \\
dydrogesterone \\
tablets $40 \mathrm{mg}$ for the \\
first time, then take 10 \\
mg once every 8 hours
\end{tabular} & $\begin{array}{l}\text { Intramuscular } \\
\text { progesterone } 20 \mathrm{mg} \\
\text { once a day }\end{array}$ & $28 \mathrm{~d}$ & $1,2,6$ \\
\hline \begin{tabular}{|l} 
Yang X \\
[9]
\end{tabular} & 2019 & 100 & 100 & $\begin{array}{l}28.72 \pm \\
3.57\end{array}$ & $\begin{array}{l}28.58 \pm \\
3.82\end{array}$ & $\begin{array}{l}11.21 \pm \\
0.57\end{array}$ & $\begin{array}{l}11.05 \pm \\
0.58\end{array}$ & $\begin{array}{l}\text { Control group + oral } \\
\text { dydrogesterone, initial } \\
40 \mathrm{mg} \text {, followed by } 10 \\
\mathrm{mg} \text { every } 8 \mathrm{~h}\end{array}$ & $\begin{array}{l}\text { intramuscular } \\
\text { progesterone dose, } 40 \\
\mathrm{mg} / \text { time, } 1 \text { time/d. }\end{array}$ & $\begin{array}{l}\text { Transferenc } \\
\text { e cure }\end{array}$ & $5 a, 5 b, 6$ \\
\hline \begin{tabular}{|l|} 
Lou Y [1] \\
\end{tabular} & 2019 & 47 & 47 & $28 \pm 4$ & $28 \pm 4$ & $\begin{array}{l}8.2 \pm \\
1.6\end{array}$ & $8.1 \pm 1.5$ & \begin{tabular}{|l|} 
Control group + \\
intramuscular \\
injection of $20 \mathrm{mg}$ \\
progesterone once a \\
day
\end{tabular} & $\begin{array}{l}\text { Oral dydrogesterone, } \\
\text { initial } 40 \mathrm{mg} \text {, followed } \\
\text { by } 10 \mathrm{mg} \text { every } 8 \mathrm{~h}\end{array}$ & $14 d$ & $1,2,3,6$ \\
\hline \begin{tabular}{|l|} 
Zhang C \\
[6]
\end{tabular} & 2018 & 120 & 125 & $24.8 \pm 5.89$ & $23.9 \pm 6.21$ & - & - & \begin{tabular}{|l|} 
Control group + oral \\
dydrogesterone 10 \\
$\mathrm{mg} /$ time, twice daily
\end{tabular} & \begin{tabular}{|l} 
Intramuscular \\
injection of \\
progesterone $20 \mathrm{ml}$, \\
once daily or oral \\
progesterone \\
capsules, 100 \\
$\mathrm{mg} /$ time, twice daily
\end{tabular} & $15 \mathrm{~d}$ & 4,6 \\
\hline \begin{tabular}{|l|}
$\operatorname{Liu} Y$ [2] \\
\end{tabular} & 2018 & 40 & 40 & $\begin{array}{l}29.72 \pm \\
3.51\end{array}$ & $\begin{array}{l}27.40 \pm \\
3.77\end{array}$ & $\begin{array}{l}6.27 \pm \\
2.69\end{array}$ & $\begin{array}{l}7.81 \pm \\
3.02\end{array}$ & \begin{tabular}{|l|} 
Control group + \\
intramuscular \\
progesterone $40 \mathrm{mg}$ \\
each time, once a day, \\
the dose can be \\
changed to $20 \mathrm{mg}$ \\
after symptom relief
\end{tabular} & $\begin{array}{l}\text { Oral dydrogesterone } \\
40 \mathrm{mg} \text {, twice daily, } \\
\text { changed to } 10 \mathrm{mg} \\
\text { after } 8 \mathrm{~h}\end{array}$ & \begin{tabular}{|l|} 
Transferenc \\
e cure
\end{tabular} & $\begin{array}{l}1,3,4,5 a, \\
5 b\end{array}$ \\
\hline \begin{tabular}{|l|} 
Chen X \\
{$[3]$}
\end{tabular} & 2017 & 53 & 53 & $25.9 \pm 5.4$ & $26.8 \pm 5.2$ & $\begin{array}{l}8.5 \pm \\
1.2\end{array}$ & $7.9 \pm 1.6$ & \begin{tabular}{|l|} 
Control group + \\
intramuscular \\
injection of $20 \mathrm{mg}$ \\
progesterone once a \\
day
\end{tabular} & $\begin{array}{l}\text { Oral dydrogesterone, } \\
\text { initial } 40 \mathrm{mg} \text {, followed } \\
\text { by } 10 \mathrm{mg} \text { every } 8 \mathrm{~h}\end{array}$ & $14 d$ & $1,2,3,4$ \\
\hline \begin{tabular}{|l|} 
Wang Q \\
{$[10]$}
\end{tabular} & 2019 & 40 & 40 & $\begin{array}{l}27.63 \pm \\
2.43\end{array}$ & $\begin{array}{l}27.51 \pm \\
2.39\end{array}$ & $\begin{array}{l}8.36 \pm \\
1.22\end{array}$ & $\begin{array}{l}8.33 \pm \\
1.28\end{array}$ & $\begin{array}{l}\text { Control group + oral } \\
\text { administration of } \\
\text { progesterone tablets } \\
(20 \mathrm{mg} / \mathrm{d}, \text { twice })\end{array}$ & $\begin{array}{l}\text { Oral progesterone } 200 \\
\mathrm{mg} / \mathrm{d} \text {, twice }\end{array}$ & \begin{tabular}{|l|} 
Transferenc \\
e cure
\end{tabular} & $\begin{array}{l}1,2,3,5 \mathrm{a} \\
5 \mathrm{~b}\end{array}$ \\
\hline \begin{tabular}{|l} 
Peng $Y$ \\
{$[7]$}
\end{tabular} & 2018 & 45 & 45 & $\begin{array}{l}28.11 \pm \\
2.96\end{array}$ & $\begin{array}{l}27.04 \pm \\
2.99\end{array}$ & $\begin{array}{l}6.98 \pm \\
1.21\end{array}$ & $\begin{array}{l}7.13 \pm \\
1.05\end{array}$ & $\begin{array}{l}\text { Control group + oral } \\
\text { administration of } \\
\text { dydrogesterone, } 30 \\
\mathrm{mg} \text { for the first time, } \\
\text { followed by } 10 \\
\mathrm{mg} / \text { time, } 3 \text { times } / \mathrm{d}\end{array}$ & \begin{tabular}{|l} 
Intramuscular \\
injection of \\
progesterone 35 \\
$\mathrm{~mL} /$ time, 1 time/d
\end{tabular} & $15 d$ & 4,6 \\
\hline
\end{tabular}

T, experimental group; C, control group; 1, P; 2, E2; 3, HCG; 4, fetal effective rate; 5, symptom disappearance time (a: bleeding; b: abdominal pain); 6, safety. 

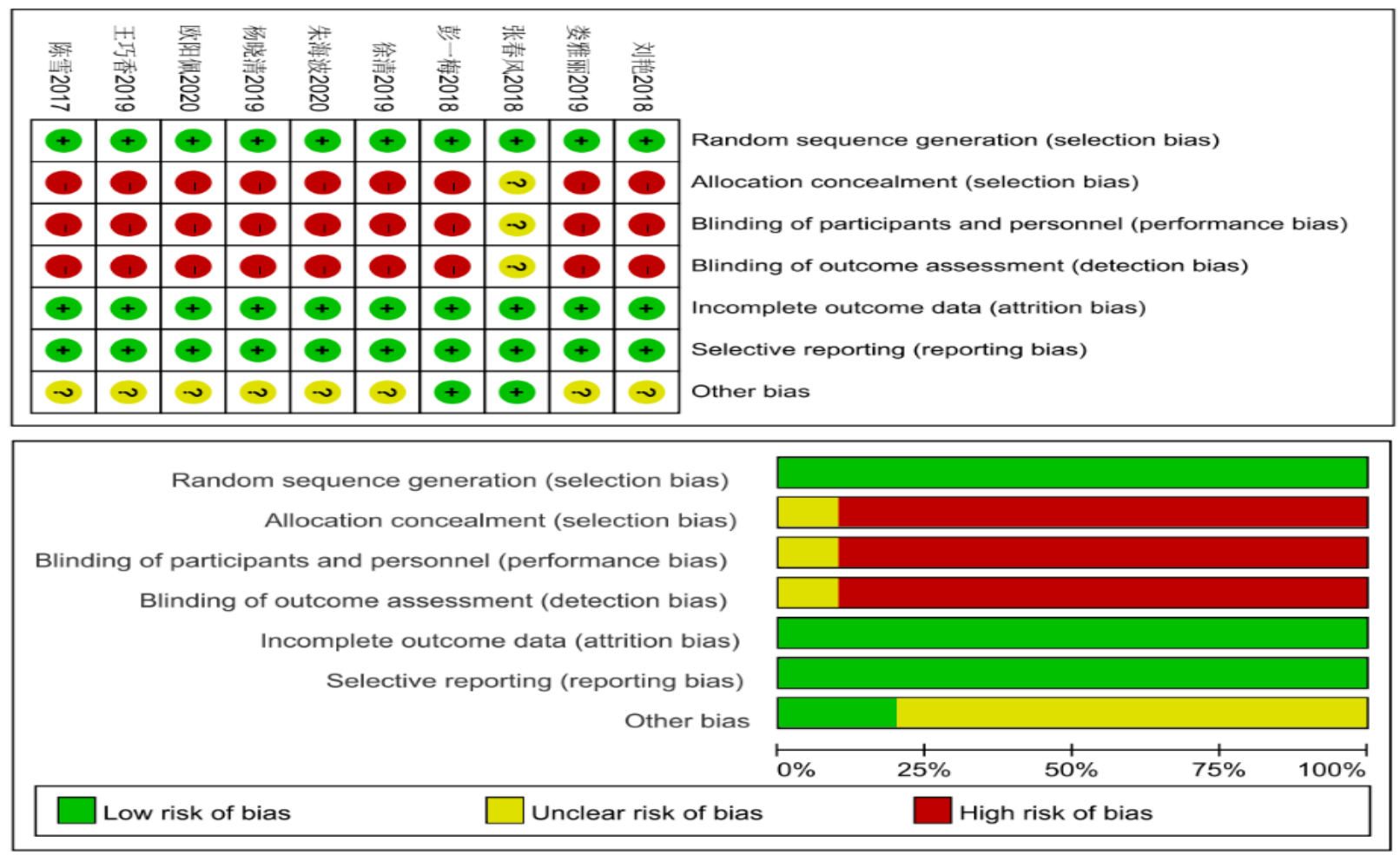

Figure 1. Basic characteristics and quality evaluation results

\section{Meta-analysis}

A total of 5 articles $(n=625)$ evaluated the effective rate of fetal protection ${ }^{[2,3,5-7]}$. Heterogeneity test showed that the heterogeneity was small $(\mathrm{P}=0.24, \mathrm{I} 2=27 \%)$, so fixed effect model analysis was used. The effective rate of combined medication was higher than that of control group ( $\mathrm{OR}=0.14,95 \% \mathrm{CI}$ [0.07,0.27], $\mathrm{P}<$ 0.00001), and there was statistical difference between the two groups. See Figure 2. Eight articles (n=959) evaluated the safety ${ }^{[1,5-11]}$. The heterogeneity test showed that the heterogeneity was large $(\mathrm{P}<0.0001$, $\mathrm{I} 2=79 \%$ ), so the random effect model analysis showed that the safety of the combination group was significantly better than that of the control group $(\mathrm{OR}=3.09,95 \% \mathrm{CI}[1.13,8.48], \mathrm{P}=0.03)$, with statistical difference between groups, as shown in Figure 3.

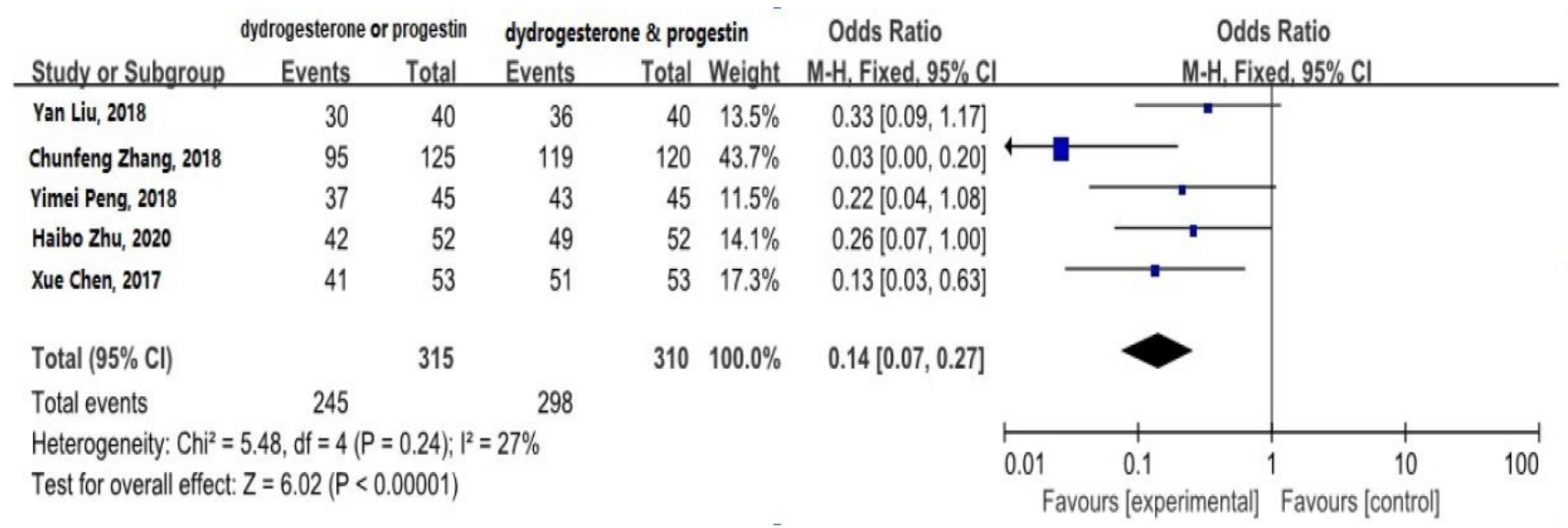

Figure 2. Effective rate of tire protection 


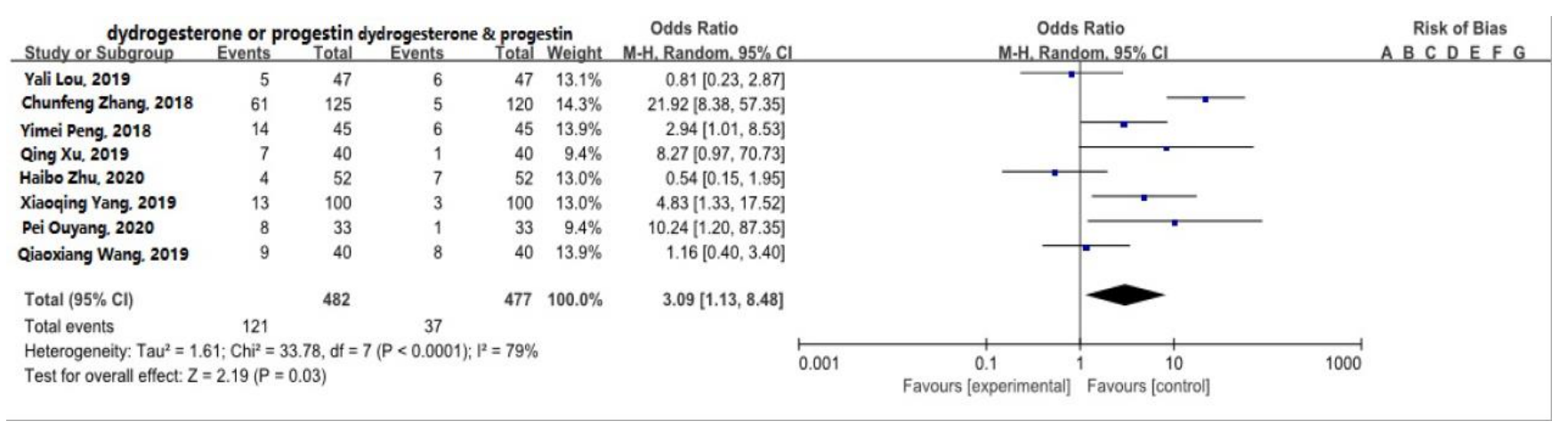

Figure 3. Security

\section{Discussion}

Through meta-analysis of 10 included articles, the results showed that the combination group was better than the control group in improving the efficiency and safety of fetal protection. Dydrogesterone combined with progesterone in the treatment of luteal insufficiency abortion, to a certain extent, can avoid the occurrence of serious complications in patients, so the combination of drugs is very beneficial for pregnant women ${ }^{[7]}$. Didroxyprogesterone is a natural progesterone, which is well absorbed in the body. It can reduce the rejection of the embryo through the immune regulation of the mother so as to maintain and protect pregnancy ${ }^{[12]}$. In pregnant women, the use of progesterone can reduce the excitability of the uterus and inhibit its activity ${ }^{[13]}$, so as to protect the fetus in vivo and promote the growth and development of the fetus ${ }^{[14]}$. This meta-analysis shows that the clinical efficacy of diltraprogesterone combined with progesterone in the treatment of threatened abortion with luteal insufficiency is significantly improved, the hormone level of patients is significantly improved, the success rate of fetal protection is improved, and the safety is higher, which is conducive to the early recovery of patients, and is worthy of clinical promotion and application ${ }^{[11]}$.

\section{Funding}

Social Development Science and Technology Project (Project name: Clinical study on the effect of electroacupuncture combined with walking through the meridian on body mass index, glucose metabolism and reproductive endocrine in patients with obese polycystic ovary syndrome; Project no.: 2016SF-362), and Special Project of Natural Science (Project name: Association of endometrial precancerous lesions with insulin resistance and adiponectin based on high incidence of diabetes mellitus; Project no.: 13JK0800)

\section{Disclosure statement}

The author declares no conflict of interest.

\section{References}

[1] Lou Y, 2019, Effect of Progesterone Combined with Progesterone on Hormone Levels in Patients with Threatened Abortion with Luteal Insufficiency. Journal of Practical Medical Technology, 26(8): 10601062.

[2] Liu Y, 2018, Treatment of Threatened Abortion with Luteal Insufficiency by Didroxyprogesterone and Progesterone. Shenzhen Journal of Integrated Traditional Chinese and Western Medicine, 28(18): 105 106. 
[3] Chen X, 2017, Observation on the Effect of Didroxyprogesterone Combined with Progesterone in the Treatment of Threatened Abortion Caused by Luteal Insufficiency. Journal of Contemporary Medicine, 15(23): 145-146.

[4] Xie X, Gou W, 2013, Obstetrics and Gynecology, 8th Edition, People's Health Publishing House, Beijing, 48.

[5] Zhu H, 2020, Analysis of the Effect of Progesterone Combined with Progesterone on Threatened Abortion with Luteal Insufficiency [J]. Chinese Journal of Medicine and Clinic, 20(9): 1525-1527.

[6] Zhang C, 2018, The Application Value of Didroxyprogesterone in the Treatment of Threatened Abortion with Luteal Insufficiency. Journal of Contemporary Medicine, 16(23): 157-158.

[7] Peng Y, 2018, Study on the Curative Effect of Dedrogesterone Combined with Progesterone in the Treatment of Luteal Insufficiency Abortion. China Modern Drug Application, 12(5): 133-134.

[8] Xu Q, 2019, The Clinical Effect of Progesterone and Progesterone in the Treatment of Threatened Abortion with Luteal Insufficiency. Chinese Medical Guide, 17(33): 17.

[9] Yang X, 2019, Clinical Effect of Oral Dydrogesterone Combined with Intramuscular Progesterone in the Treatment of Threatened Abortion with Luteal Insufficiency. Clinical Medical Research and Practice, 4(25): 101-103.

[10] Wang Q, 2019, Effects of Progesterone Combined with Didroxyprogesterone on Hormone Levels and Cytokines in Patients with Luteal Insufficiency Induced Abortion. Chinese School Doctor, 33(3): 210 213.

[11] Ouyang P, 2020, Clinical Efficacy of Progesterone Combined with Progesterone in the Treatment of Threatened Abortion with Luteal Insufficiency. Journal of Clinical Rational Drug Use, 13(3): 32-33.

[12] Li LL, Yin C, Jiang L, 2017, Clinical Effect of Progesterone and Progesterone in the Treatment of Threatened Abortion with Luteal Insufficiency. Journal of Practical Gynecological Endocrinology (Electronic Edition), 4(10): $45+47$.

[13] Liang J, Luo F, Li X, et al., 2020, A Meta-analysis on Infertility Caused by Polycystic Ovary Syndrome by Bushen Huoxue Method. Journal of Hainan Medical College, 26(3): 219-225.

[14] Fan L, Xue X, Zhang Y, et al., 2017, Clinical Study on the Treatment of Threatened Abortion with Luteal Insufficiency by Single or Combined Use of Progesterone and Progesterone. Drug Evaluation Research, 40(3): 381-384. 